\title{
Transcranial duplex doppler ultrasonography in dogs with hydrocephalus
}

\author{
[Ultrassonografia duplex Doppler transcraniana em cães com hidrocefalia] \\ C.F. Carvalho ${ }^{1,6}$, M.C. Chammas $^{2}$, J.P. Andrade Neto ${ }^{3}$, C.D. Jimenez ${ }^{4}$, S.A. Diniz ${ }^{4}$, G.G. Cerri ${ }^{5}$ \\ ${ }^{1}$ Serviço de ultrassonografia - PROVET - São Paulo, SP \\ ${ }^{2}$ Instituto de Radiologia do Hospital das Clínicas - FMUSP - São Paulo, SP \\ ${ }^{3}$ Universidade Anhembi-Morumbin - São Paulo, SP \\ ${ }^{4}$ Médica veterinária autônoma \\ ${ }^{5}$ Faculdade de Medicina - USP - São Paulo, SP \\ ${ }^{6}$ Pesquisadora do INRAD-HCFMUSP
}

\begin{abstract}
Transcranial duplex Doppler ultrasound was performed in 32 conscious dogs presenting ventriculomegaly detected in B-mode, obtaining measures of lateral ventricles and resistance parameters of main cerebral arteries before and after 30 days of clinical treatment. The animals were distributed divided in two groups: group 1, dogs that presented remission or decrease of the neurological signs of the disease after clinical therapy; and group 2, dogs that displayed worsening of the neurological signs or clinical stability. The data were all presented in tables and were submitted to paired t test and to logistic regression models to evaluate the influence of the RI reduction on both groups. There was no significant influence of the variables in the B-mode. After the treatment, the mean resistive index (RI) was significantly lower for the group that presented clinical improvement. There was no significant difference of the mean RI reduction for the same artery when the right and left sides were compared. It could be concluded that transcranial duplex Doppler ultrasound is a method of cerebral hemodynamic assessment able to monitor more precisely the treatment of hydrocephalus in dogs and verify the responses.
\end{abstract}

Keywords: dog, Doppler ultrasonography, neurology, hydrocephalus

\section{RESUMO}

Foi realizada a ultrassonografia duplex Doppler transcraniana em 32 cães, conscientes, que apresentavam ventriculomegalia previamente detectada ao exame modo-B, para obter as medidas dos ventrículos laterais e os parâmetros de resistência das artérias cerebrais antes e depois de 30 dias de tratamento clínico. Os animais foram distribuídos em dois grupos: 1 - formado por cães que apresentaram remissão ou diminuição dos sinais clínicos após tratamento; 2 - por cães que apresentaram piora dos sinais neurológicos ou estabilidade do quadro clínico. Todos os dados foram dispostos em tabelas e submetidos ao teste t pareado e a modelos de regressão logística para avaliar a influência da redução do índice de resistividade (IR). Não foi observada influência das variáveis em modo-B. Após o tratamento, a média do IR foi significantemente menor para o grupo que apresentou melhora clínica; não houve diferença significativa da média de redução do IR para a mesma artéria quando comparados os lados direito e esquerdo. Concluiu-se que o duplex Doppler transcraniano é um métodos de avaliação hemodinâmica capaz de monitorar mais precisamente o tratamento da hidrocefalia em cães e verificar a resposta dos pacientes.

Palavras-chave: cão, ultrassonografia Doppler, neurologia, hidrocefalia

Recebido em 20 de maio de 2009

Aceito em 28 de dezembro de 2009

E-mail: cibelefcarvalho@terra.com.br 


\section{INTRODUCTION}

In human, numerous cerebral vessels have been mapped and their parameters have been characterized using transcranial Doppler ultrasonography (Assis e Machado, 1999). However, a few veterinary reports have evaluated the canine brain in a limited population of patients (Hudson et al., 1997, 1998; Nautrup and Tobias, 2000; Seo et al., 2005). Transcranial ultrasonography has become the initial examination of human infants or neonates with suspected hydrocephalus (Abraão et al., 1998). There are some veterinary reports that describe ultrasonographic anatomy of the brain (Hudson et al., 1989, 1991; Tucker and Gavin, 1996). Location of cerebral arteries was reported in dogs using B-mode (Hudson et al., 1989) or transcranial duplex Doppler (Seo et al., 2005). Probably, the most common application of ultrasonography of the brain is to determine the size of the lateral ventricles in toy-breed dogs suspected of having hydrocephalus (Hudson et al., 1989).

Some authors studied the relationship among basilar artery resistance, degree of ventriculomegaly, and clinical signs in hydrocephalic dogs (Saito et al., 2003). Others studied 37 normal dogs using transcranial Doppler ultrasound to determine the resistive index (RI) values of normal canine cerebral arteries (Seo et al., 2005). In that study, they observed that there was no significant difference of RI obtained using fontanelle window and temporal window, between male and female and between rostral and caudal cerebral arteries. The normal resistive index was $0.55 \pm 0.04$. Some reports demonstrate significant correlation between resistive index and transcranial pressure in humans (Goh et al., 1992; Rainov et al., 2000).

Prevalence studies in dogs indicate that congenital anomalies constitute approximately $6 \%$ of total diagnoses (Selby et al., 1979). Hydrocephalus accounts for one half of these anomalies, making it one of the more common canine congenital defect (Spaulding and Sharp, 1990). Small and brachicephalic dogs represent high risk to present hydrocephalus (Spaulding and Sharp, 1990). Many patients may present obscure signals of hydrocephalus and the significance of ventriculomegaly can be difficult to determine, rendering the diagnosis difficult.
Sonographic imaging may demonstrate ventriculomegaly but the parameters obtained in the B-mode are not suitable for monitoring the treatment and clinical evolvement of this disease (Spaulding and Sharp, 1990; Tucker and Gavin, 1996).

There are reports in veterinarian literature that correlates resistive index of the basilar artery and clinical signs in hydrocephalic dogs and other brain injuries finding relationship among them (Fukushima et al., 1999, 2000). Researches showed that induced acute hydrocephalus in cats leads to a reduction of $22 \%$ in the blood flow of the brain, cerebellum, and encephalic trunk (Hochwald et al., 1975). Besides, the changes in brain circulation as a result of hydrocephalus may alter the caliber of cerebral arteries in variable ways in each part of the encephalon. Monitoring these arteries in the course of hydrocephalus may be useful to determine the correct moment to submit the patient to a surgery and to further assess the adequate functioning of the cerebrospinal fluid shunts.

Transcranial duplex Doppler is a non invasive and relatively inexpensive method of diagnostic imaging compared to magnetic resonance and computer tomography. The aim of this current study was to check the possibility of monitoring treatment and clinical evolvement of the disease by means of RI evaluation of the main brain arteries in dogs with hydrocephalus.

\section{MATERIAL AND METHODS}

Thirty-two dogs of nine different breeds and with age ranging from three-month-old to seven-yearold were examined. The animals had been sent to perform transcranial Doppler ultrasonography after diagnosis of ventriculomegaly detected by B-mode ultrasound. The exam was performed on two occasions: before clinical treatment and after 30 days of clinical therapy with diuretics and corticoids. The animals were distributed in two groups according to the clinical response. In group 1, dogs presented remission or decrease of the neurological signs of the disease after clinical therapy; and in group 2, dogs displayed worsening of the neurological signs or clinical stability. According to the clinical response, the clinical improvement was rated as absent (0) when no neurological alterations to the clinical exam were observed or present (1). Neurological 
signs included: behavioral changes, postural reaction deficits, and seizures. Dogs with cardiovascular or other diseases that could produce similar neurologic symptoms were excluded. The criteria for improvement were remission or decrease of the neurological signs observed during the initial examination.

This work was approved by the Research and Ethic Committee of INRAD (Radiology Institute), from the Faculdade de Medicina at the Universidade de São Paulo. The owners signed an informed consent allowing the use of the data in this research.

It was used a duplex Doppler GE Ultrasound ${ }^{\circledR}$, model LOGIQ3 with multifrequencial transducers, one convex scan with 3.0 to 5.0 $\mathrm{MHz}$, another with 4.0 to $6.0 \mathrm{MHz}$, and a linear scan with 7.0 to $10.0 \mathrm{MHz}$.

All the dogs had their hair of head clipped and coupling gel to ultrasound was used. Sedation was not necessary, because all dogs were positioned in a comfortable way. They were positioned in sternal decubit or sitting on the table using temporal window or rostral fontanelle window as necessary. Vertebrobasilar system was imaged from the foramen magnum. The exam was carried out before and after the clinical treatment and its duration was measured with a chronometer. It was performed by the same professional in this sequence - B-mode, color Doppler, and pulsed Doppler ultrasonography as follow: a - bidimensional mode ultrasonography: brain was examined in sagittal, transversal, and dorsal planes (Fig. 1A and 1B). It was observed brain parenchimal tissue: measure cerebral mantle thickness or the distance of the roof of ventricle to the brain surface as described in literature by Hudson et al. (1989); cerebral echogenicity that was variable but it was considered normal when iso or hyperechogenic to thalamo as described by Fukushima et al. (2000); lateral ventricles and third ventricle (measure the distance of the bottom to the roof of ventricle in sagittal and transversal planes). b Color Doppler: after B-mode ultrasonography brain was mapped by conventional color Doppler to study vascular architecture (Fig. 2). Cerebral arteries (rostral, middle, and caudal) were found in right and left sides, and internal carotids and vertebrobasilar system were also seen. c - Pulsed Doppler: with help of color Doppler imaging, pulsed Doppler cursor was positioned at cerebral arteries (rostral, middle, and caudal) in both right and left sides on temporal or opened rostral fontanelle windows. When the trace was free of artifacts and after correction of the angle of insonation, image was frozen and the waveforms were analyzed (Fig. 3). Maximal systolic peak velocity, final diastolic velocity, and resistive index were calculated in each vessel by ultrasound machine software.

The data presented in tables were submitted to paired t test with confidence interval of $95 \%$ or statistical significance defined as $\mathrm{P}<0.05$. The upper and the lowest limits of these intervals were built using mean \pm standard error. In this study, the clinical improvement of the patient was a binary response, recorded as either absent (0) or present (1); so logistic regression models were used to evaluate the influence of the RI reduction on both groups.

\section{RESULTS AND DISCUSSION}

Ventriculomegaly was determined by means of the measurement of the lateral ventricles, as described in the literature (Spaulding and Sharp, 1990). From the 32 examined animals with ventriculomegaly, the following breed distribution was obtained: Poodle (7/32 or $22 \%)$, Yorkshire (7/32 or 22\%), Pinscher $(5 / 32$ or $15.5 \%$ ), Lhasa Apso (4/25 or $12.5 \%$ ), Maltese (3/32 or $9.5 \%)$, Pekingnese $(1 / 32$ or $3 \%)$, Spitz $(1 / 32$ or $3 \%)$, and Teckel $(1 / 32$ or $3 \%)$. Breed distribution in this study was coincident with that described elsewhere (Hochwald et al., 1975; Andrade Neto, 2004). There were some sexual predispositions: 17 female $(53 \%)$ and 15 male (47\%). Age ranged from three-month-old to seven-year-old, but 19 (59\%) were younger than two-year-old as described in literature (Braund, 1994). 

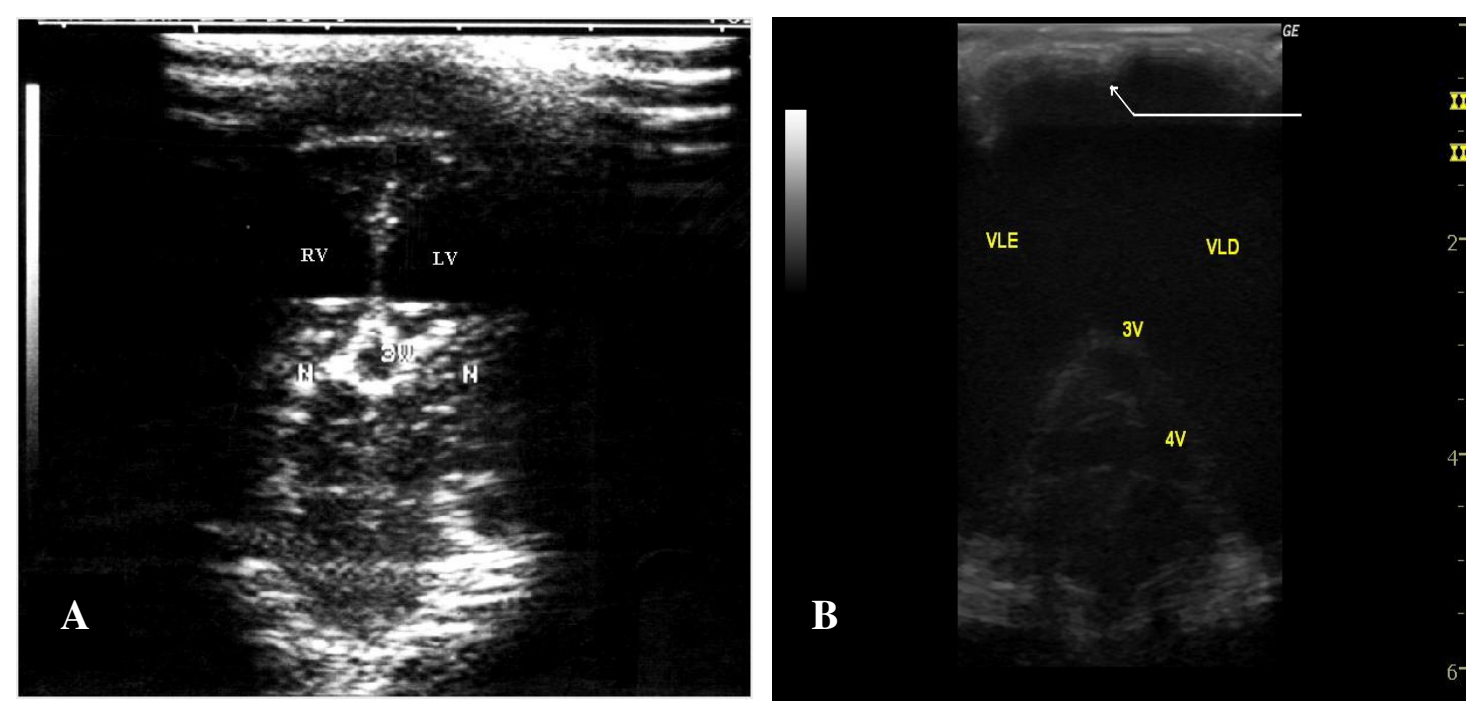

Figure 1. A) Transcranial B-mode ultrasonography of ventriculomegaly seen in a dog with hydrocephalus - RV: right ventricle; $\mathrm{LV}$ : left ventricle; $3 \mathrm{~V}$ : third ventricle; $\mathrm{N}$ : basal nucleus. B) transcranial B-mode ultrasonography of bilateral ventriculomegaly in a dog with interventricular communication and corpus callosum absent - VLE: left ventricle; VLD: right ventricle; 3V: third ventricle; $4 \mathrm{~V}$ : fourth ventricle.

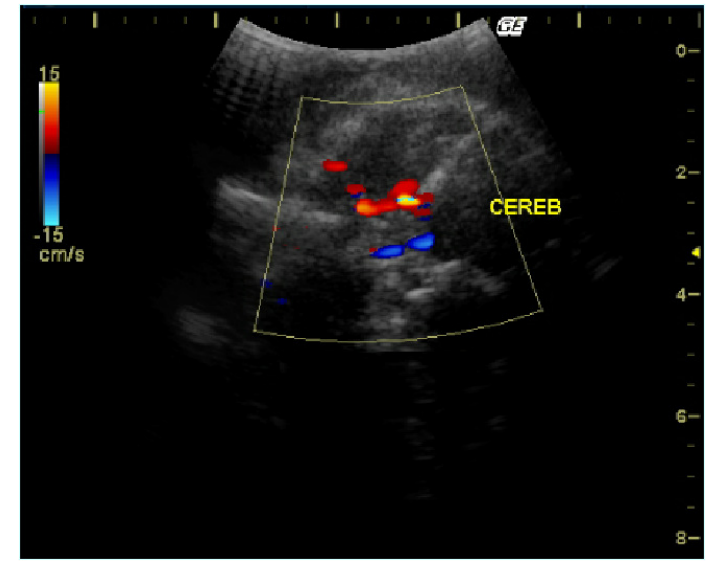

Figure 2. Duplex Doppler imaging of arterial circle of Willis in a dog with hydrocephalus. CEREB: cerebellum.

Bilateral symmetric ventriculomegaly (Fig. 1A) was observed in all dogs. Ventricular communication was observed in seven dogs $(7 / 32$ or $22 \%)$ as described in literature (Spaulding and Sharp, 1990), with one of them displaying absence of corpus callosum and septum pellucidum (Fig. 1B).

Time of examination ranged from 20 to 30 minutes, with average of 23 minutes. All the exams were carried out by the same examiner and the duration of the exam was more

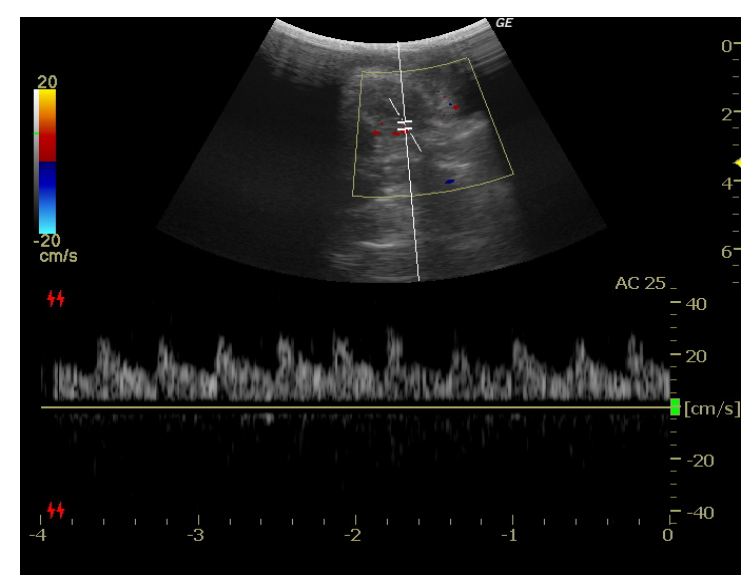

Figure 3. Doppler spectral mapping of rostral cerebral artery in a dog with hydrocephalus.

prolonged in the less cooperative animals. Besides, increased rapidity in the assessment of the cerebral arteries was noticed as the experience of the examiner grew. It is believed that growing experience may lead to easy and fast accomplishment of the exam. Rostral fontanelle was opened in 12 dogs $(37.5 \%)$ and closed in $20(62.5 \%)$. Seo et al. (2005) showed that rostral cerebral artery was more difficult to be identified using transtemporal window than in transverse and sagittal scans of dogs with open fontanelle using transfontanelle window. In this 
present study, it was noticed that when rostral fontanelle is constant, this window may facilitate the assessment of the rostral cerebral arteries as cited in the literature. However, when it is closed, temporal window may provide a good observation of the rostral, middle, and caudal cerebral arteries.

The animals were distributed according to the clinical response. Comparing the mean of the lateral ventricles dimensions before and after the treatment in both groups, no statistical significant decrease could be observed (Table 1). Thus, it can be said that a decrease in the dimensions of the lateral ventricles is not always expected even in the presence of an improvement or stabilization of neurological clinical symptoms. As previously described (Spaulding and Sharp, 1990), the dimensions of the ventricles are not correlated with the clinical symptomatology of the animals with hydrocephalus. Even when logistic regression models were applied, it could be noticed that there is no significant influence of the variables in the B-mode (measurements of the ventricles before and after medicine administration, presence of open fontanelle, and communication between lateral ventricles) in relation to improvement of the patient. These results confirm those previously described in the literature (Hudson et al., 1990; Spaulding and Sharp, 1990).

Table 1. Measures of the ventricles obtained in B-mode transcranial ultrasonography of dogs with hydrocephalus before and after clinical treatment, from January to December 2005

\begin{tabular}{|c|c|c|c|c|c|c|}
\hline Animal & $\begin{array}{c}\text { RLV }(\mathrm{cm}) \\
\text { before }\end{array}$ & $\begin{array}{c}\mathrm{RLV}(\mathrm{cm}) \\
\text { after }\end{array}$ & $\begin{array}{c}\text { LLV }(\mathrm{cm}) \\
\text { before }\end{array}$ & $\begin{array}{c}\text { LLV }(\mathrm{cm}) \\
\text { after }\end{array}$ & $\begin{array}{c}3^{\text {rd }} \mathrm{V}(\mathrm{cm}) \\
\text { before }\end{array}$ & $\begin{array}{c}3^{\mathrm{rd}} \mathrm{V}(\mathrm{cm}) \\
\text { after }\end{array}$ \\
\hline 01 & 0.58 & 0.60 & 0.60 & 0.60 & 0.5 & 0.5 \\
\hline 02 & 0.84 & 0.80 & 0.82 & 0.80 & 0.2 & 0.5 \\
\hline 03 & 0.52 & 0.52 & 0.52 & 0.52 & 0 & 0 \\
\hline 04 & 0.60 & 0.60 & 0.60 & 0.60 & 0 & 0 \\
\hline 05 & 0.61 & 0.62 & 0.62 & 0.62 & 0 & 0 \\
\hline 06 & 0.67 & 0.65 & 0.67 & 0.65 & 0 & 0 \\
\hline 07 & 0.73 & 0.80 & 0.71 & 0.80 & 0.8 & 0.8 \\
\hline 08 & 0.49 & 0.50 & 0.48 & 0.50 & 0 & 0 \\
\hline 09 & 0.53 & 0.56 & 0.54 & 0.56 & 0 & 0 \\
\hline 10 & 0.46 & 0.45 & 0.46 & 0.45 & 0 & 0 \\
\hline 11 & 0.62 & 0.60 & 0.62 & 0.60 & 0 & 0 \\
\hline 12 & 0.40 & 0.40 & 0.41 & 0.40 & 0 & 0 \\
\hline 13 & 1.33 & 1.50 & 1.32 & 1.50 & 0.6 & 0.5 \\
\hline 14 & 0.41 & 0.40 & 0.40 & 0.40 & 0 & 0 \\
\hline 15 & 0.63 & 0.60 & 0.61 & 0.60 & 0 & 0 \\
\hline 16 & 3.23 & 3.25 & 3.25 & 3.25 & 1.15 & 1.0 \\
\hline 17 & 0.51 & 0.51 & 0.51 & 0.51 & 0 & 0 \\
\hline 18 & 1.70 & 1.70 & 1.69 & 1.70 & 0 & 0 \\
\hline 19 & 1.26 & 1.22 & 1.25 & 1.22 & 0 & 0 \\
\hline 20 & 0.68 & 0.68 & 0.68 & 0.68 & 0 & 0 \\
\hline 21 & 1.34 & 1.35 & 1.35 & 1.35 & 0 & 0 \\
\hline 22 & 0.48 & 0.50 & 0.49 & 0.50 & 0 & 0 \\
\hline 23 & 0.77 & 0.80 & 0.76 & 0.80 & 0 & 0 \\
\hline 24 & 0.63 & 0.63 & 0.63 & 0.63 & 0 & 0 \\
\hline 25 & 0.61 & 0.60 & 0.60 & 0.60 & 0.3 & 0.5 \\
\hline 26 & 1.17 & 1.15 & 1.15 & 1.15 & 0.4 & 0.5 \\
\hline 27 & 0.80 & 0.92 & 0.81 & 0.92 & 0 & 0 \\
\hline 28 & 0.95 & 0.95 & 0.97 & 0.95 & 0.3 & 0.3 \\
\hline 29 & 2.25 & 2.20 & 2.20 & 2.20 & 0.6 & 0.5 \\
\hline 30 & 0.85 & 0.85 & 0.85 & 0.85 & 0.25 & 0.3 \\
\hline 31 & 0.92 & 1.0 & 0.91 & 1.0 & 0 & 0 \\
\hline 32 & 0.67 & 0.65 & 0.67 & 0.65 & 0 & 0 \\
\hline Mean & 0.88 & 0.89 & 0.87 & 0.89 & 0.16 & 0.16 \\
\hline
\end{tabular}

RLV: right lateral ventricle; LLV: left lateral ventricle; $3^{\text {rd }} \mathrm{V}$ : third ventricle. 
Researches demonstrated that the acute hydrocephalus produced in cats promotes the reduction of $22 \%$ in the blood flow of the brain, cerebellum; and encephalic trunk (Hochwald et al., 1975). Besides, the alterations that happen in the cerebral circulation due to the hydrocephalus may alter the caliber of the different cerebral arteries, leading to changes in various degrees in each portion of the encephalon (Hochwald et al., 1975). In this circumstance, the measurement of each separate cerebral artery may be of great clinical importance to study each part of the brain.

Rainov et al. (2000), studying human adult patients, verified that resistive index could reflect vascular cerebral permeability and there were a positive correlation between RI and intracranial pressure. In this study, the mean RI of the brain arteries, after the drug administration, was significantly lower in the group that presented clinical improvement or in the dogs that remained clinically stable and were classified in both groups (Fig. 4, 5, and 6). All the cases were submitted to the same treatment regarding drug, dose, and duration of therapy, excluding the possibility that an eventual difference in treatment might be responsible for changes in the RI. The treatment was interrupted or eventually changed only after the accomplishment of the second examination. When comparing the left and right sides of the same artery in the same group, the mean decrease of the RI was statistically equal (Fig. 7 and 8). Besides, it could be observed that the alterations of resistivity of the studied vessels were followed by the changes in the clinical status (Fig. 9 and 10). These results indicate that the transcranial US Doppler and RI measure can monitor the treatment of hydrocephalus in dogs more precisely than the follow-up accomplished by the B-mode. This implies that decrease in resistive index could predict an improvement in the clinical status. Vascular response and parenchyma permeability can be monitored by RI measures. The animals were examined in a time interval of 30 days. During this time gap, neither imaging examination nor daily records of clinical therapy were carried out. It is believed that if a follow-up is accomplished in a shorter time interval, the decrease in resistive index could be more precisely predicted if the resistivity drops before or after the clinical signs are noticed. Anyway, this follow up may be useful in the drug therapy adequacy and to correctly determine the moment of decision for a surgery, mainly in the cases refractory to clinical treatment.

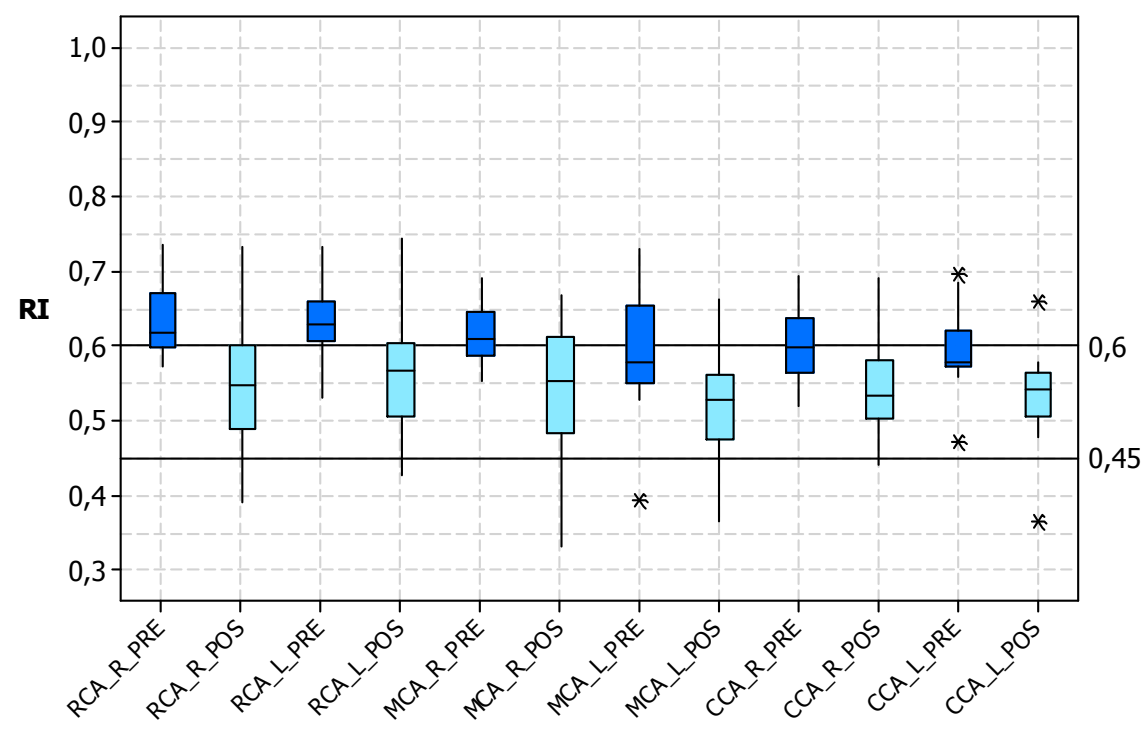

Figure 4. Boxplot graphic showing resistive index (RI) of group 1 (dogs that presented remission or decrease of neurological signs). RCA_R: right rostral cerebral artery; RCA_L: left rostral cerebral artery; MCA_R: right middle cerebral artery; MCA_L: left middle cerebral artery; CCA_R: right caudal cerebral artery; CCA_L: left caudal cerebral artery. Pre and post treatment. 


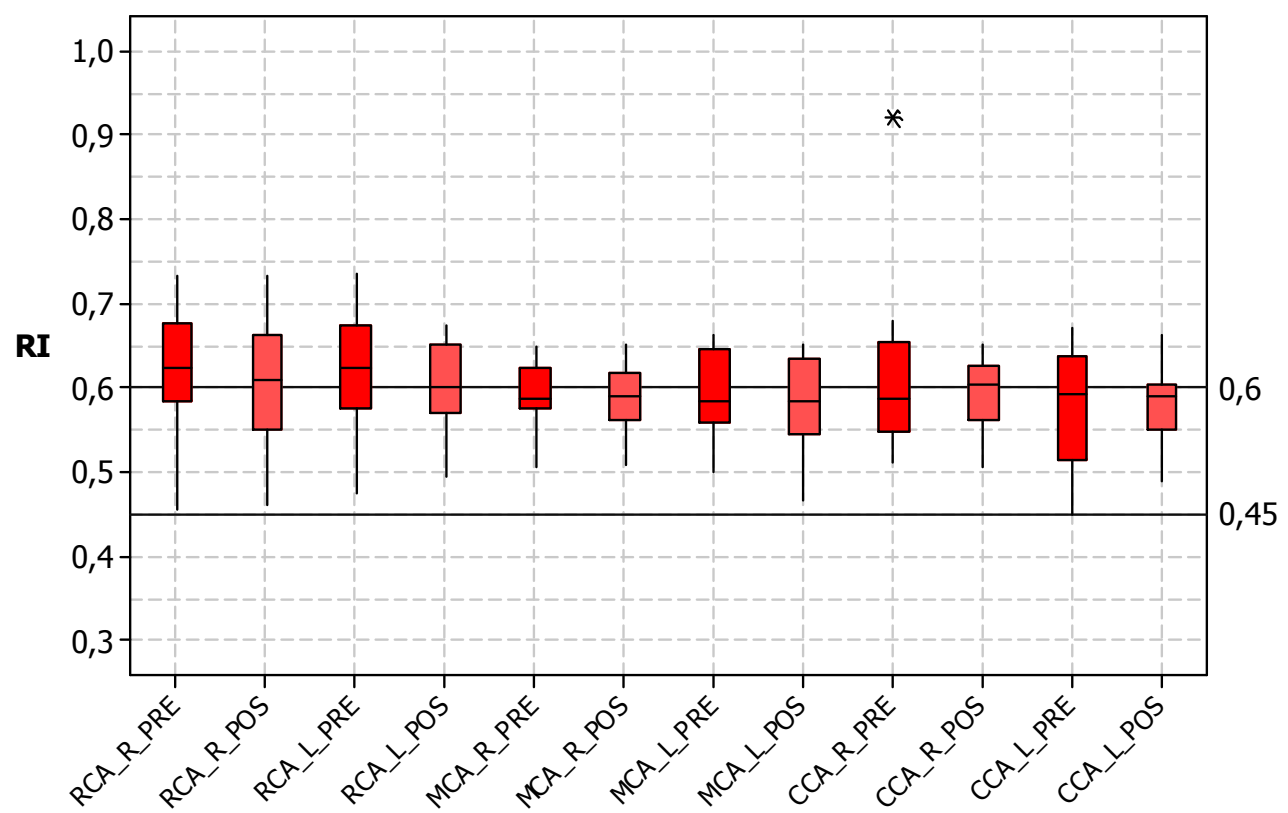

Figure 5. Boxplot graphic showing resistive index (RI) of group 2 (dogs that displayed worsening of neurological sings or clinical stability). RCA_R: right rostral cerebral artery; RCA_L: left rostral cerebral artery; MCA_R: right middle cerebral artery; MCA_L: left middle cerebral artery; CCA_R: right caudal cerebral artery; CCA_L: left caudal cerebral artery. Pre and post treatment.

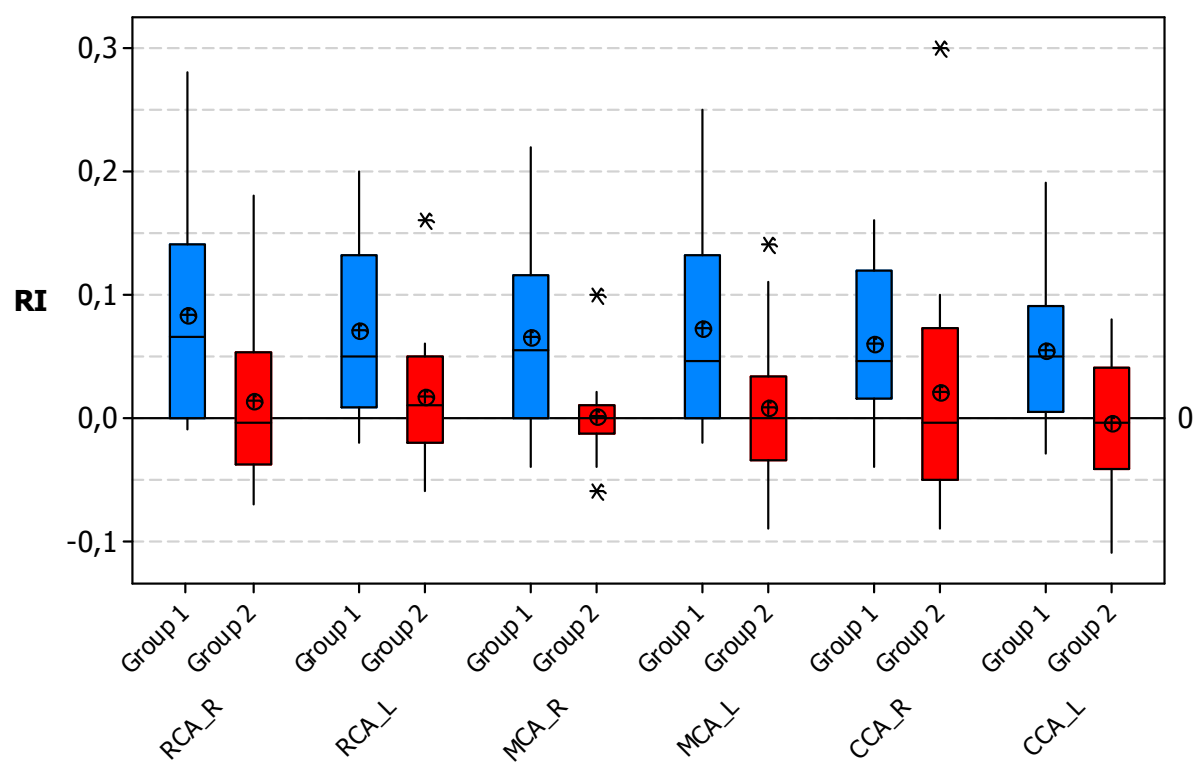

Figure 6. Boxplot graphic showing the difference between resistive index (RI) before and after treatment for group 1 (dogs that presented remission or decrease of neurological signs) and group 2 (dogs that displayed worsening of neurological sings or clinical stability). RCA_R: right rostral cerebral artery; RCA_L: left rostral cerebral artery; MCA_R: right middle cerebral artery; MCA_L: left middle cerebral artery; CCA_R: right caudal cerebral artery; CCA_L: left caudal cerebral artery. 


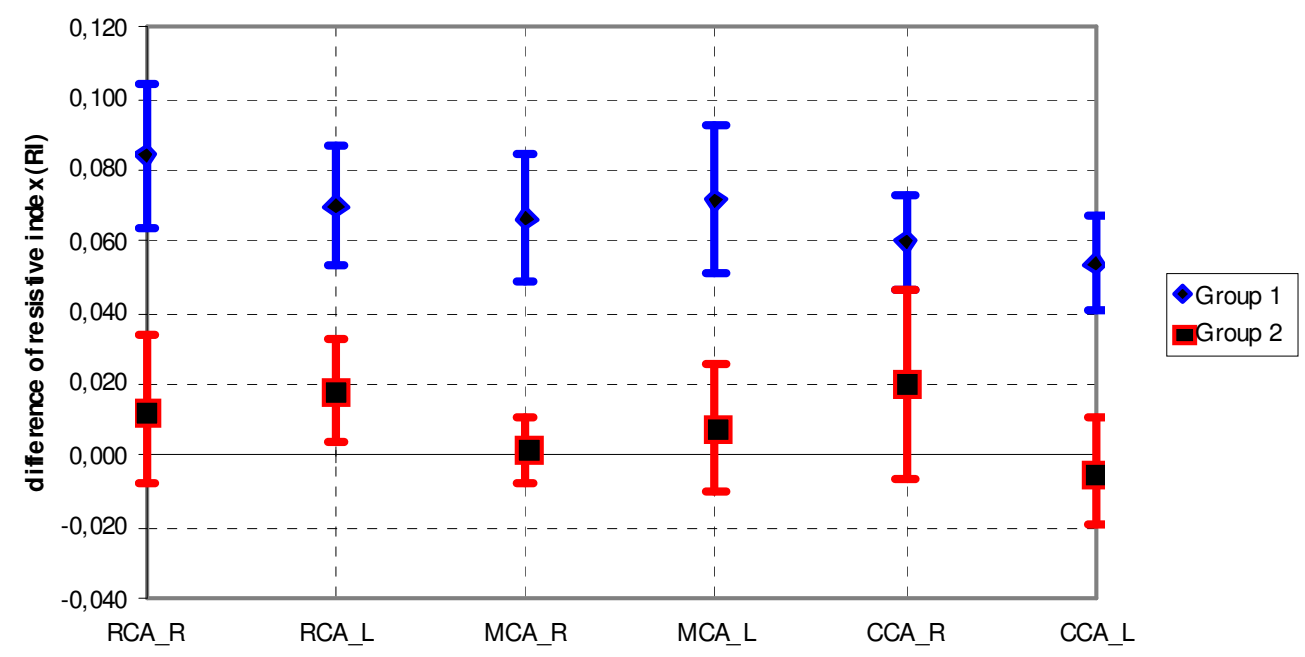

Figure 7. Means of the resistive index (RI) differences for group 1 (dogs that presented remission or decrease of neurological signs) and group 2 (dogs that displayed worsening of neurological sings or clinical stability). RCA_R: right rostral cerebral artery; RCA_L: left rostral cerebral artery; MCA_R: right middle cerebral artery; MCA_L: left middle cerebral artery; CCA_R: right caudal cerebral artery; CCA_L: left caudal cerebral artery.

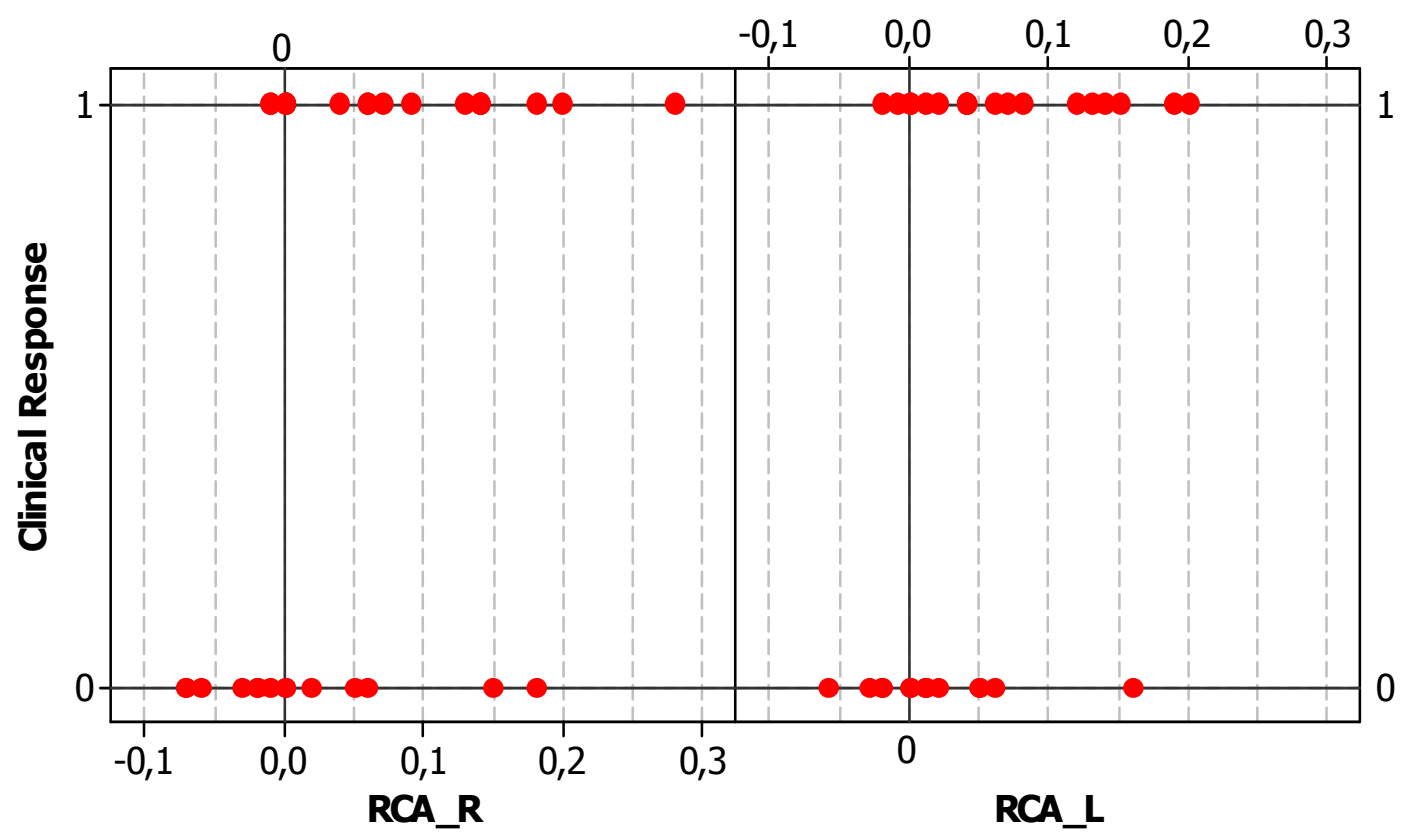

Figure 8. Scatter plot (or scattering) graphic of the resistive index (RI) difference by clinical response for right $(\mathrm{R})$ and left $(\mathrm{L})$ rostral cerebral artery (RCA); no clinical improvement (0) and clinical improvement detected (1). 


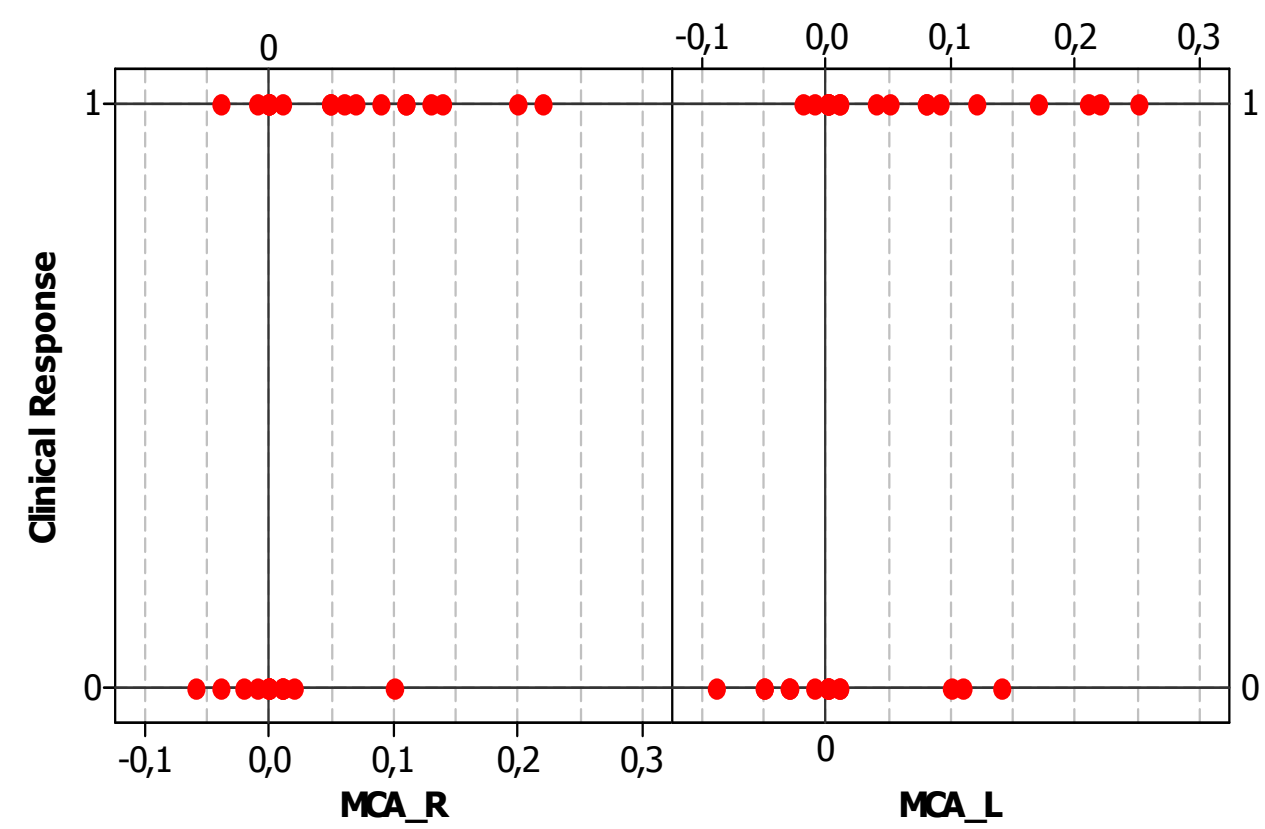

Figure 9. Scatter plot (or scattering) graphic of the resistive index (RI) difference by clinical response for right $(\mathrm{R})$ and left $(\mathrm{L})$ middle cerebral artery (MCA).

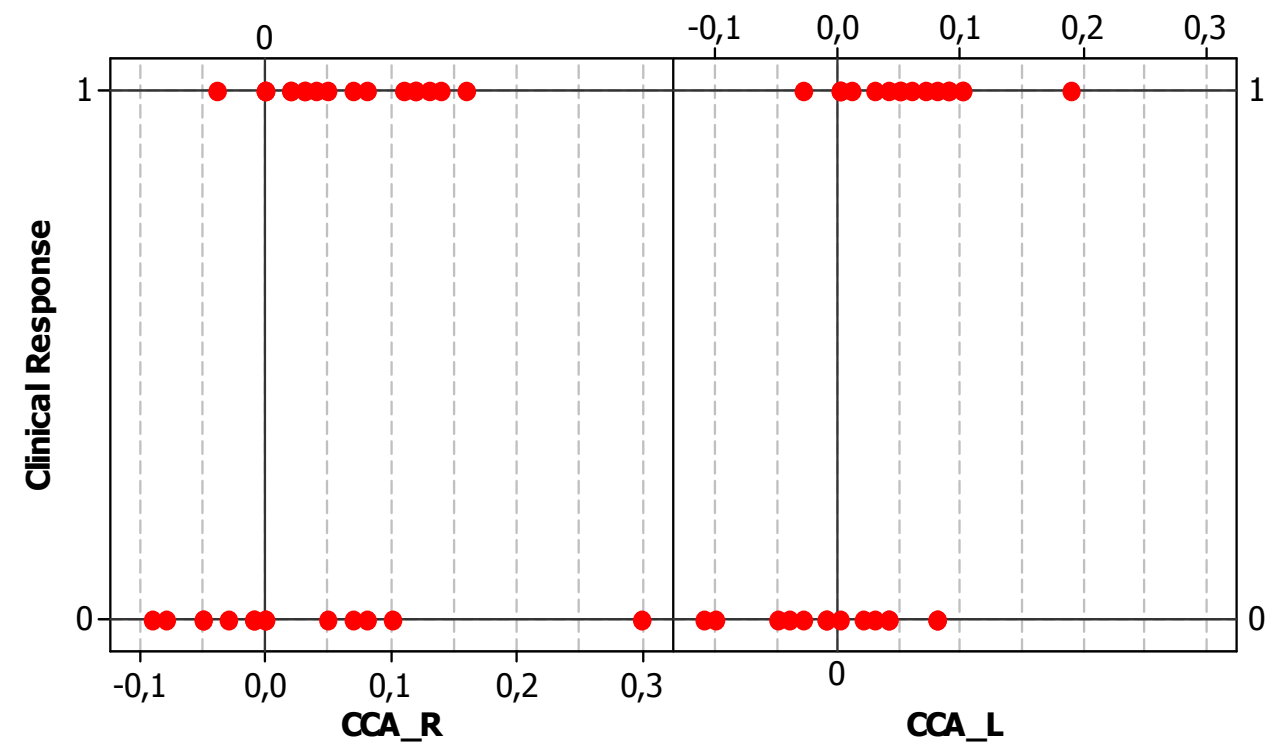

Figure 10. Scatter plot (or scattering) graphic of the resistive index (RI) difference by clinical response for right $(\mathrm{R})$ and left $(\mathrm{L})$ caudal cerebral artery $(\mathrm{CCA})$.

\section{CONCLUSIONS}

Transcranial duplex Doppler ultrasound is a method of cerebral hemodynamic assessment able to monitor clinical treatment of hydrocephalus and verify the response og the patient by measuring of resistive index of cerebral arteries. The transcranial US Doppler can more precisely monitor the treatment of hydrocephalus in dogs than evaluation of clinical signs only. In other words, the measurement of the RI is more useful than measurement of the lateral ventricles. 


\section{REFERENCES}

ABRÃO, N.; AMARO JUNIOR, E.; CERRI, G.G. Ultrassonografia intracraniana: anatomia ultrassonográfica, afecções hemorrágicas e hipoxicoisquêmicas. São Paulo: Sarvier, 1998. $125 \mathrm{p}$.

ANDRADE NETO, J.P. Ecoencefalografia. In: CARVALHO, C.F. Ultrassonografia em pequenos animais. São Paulo: Roca, 2004. p.265-276.

ASSIS, M.C.; MACHADO, H.R [Transfontanellar Doppler ultrasound measurement of cerebral blood velocity before and after surgical treatment of hydrocephalus]. Arch. Neuropsiquiatr., v.57, p.827-835, 1999.

BRAUND, K.G. Clinical syndromes in veterinary neurology. 2.ed. St. Louis: Mosby Year Book, 1994. p.113-114.

FUKUSHIMA, U.; SASAKI, S.; OKANO, S. et al. The comparison between the cerebral blood flow directly measures and cerebral blood flow velocity in the middle and basilar cerebral arteries measured by transcranial Doppler ultrasonography. J. Vet. Med. Sci., v.61, p.12931297, 1999.

FUKUSHIMA, U.; MIYASHITA, K.; OKANO, $\mathrm{S}$. et al. Evaluation of intracranial pressure by transcranial Doppler ultrasonography in dogs with intracranial hypertension. J. Vet. Med. Sci., v.62, p.353-355, 2000.

GOH, D.; MINND, R.A.; HENDRY, G.M.A. et al. Cerebrovascular resistive index assessed by Duplex Doppler sonography and its relationship to intracranial pressure in infantile hydrocephalus. Pediatr. Radiol., v.22, p.246-250, 1992.

HOCHWALD, G.M.; BOLAD, R.D.; MARLIN, A. et al. Changes in regional blood flow and water content of brain and spinal cord in acute and chronic experimental hydrocephalus. Dev. Med. Child Neurol., v.35, suppl., p.42-50, 1975.

HUDSON, J.A.; BUXTON, D.F.; COX, N.R. Color flow Doppler imaging and Doppler spectral analysis of the brain of neonatal dogs. Vet. Radiol. Ultrasound, v.38, p.313-322, 1997.
HUDSON, J.A.; CARTEE, R.E.; SIMPSON, S.T. et al. Ultrasonographic anatomy of the canine brain. Vet. Radiol., v.30, p.13-21, 1989.

HUDSON, J.A.; FINN-BODNER, S.T.; STEISS, J.E. Neurosonography. Vet. Clin. N. Am. Small Anim. Pract., v.28, p.943-971, 1998.

HUDSON, J.A.; SIMPSON, S.T.; BUXTON, D.F. et al. Ultrasonographic diagnosis of canine hydrocephalus. Vet. Radiol. Ultrasound, v.31, p.50-58, 1990.

HUDSON, J.A.; SIMPSON, S.T.; COX, N.R. et al. Ultrasonographic examination of the normal canine neonatal brain Vet. Radiol. Ultrasound, v.32, p.50-59, 1991.

NAUTRUP, C.P.; TOBIAS, R. An atlas and textbook of diagnostic ultrasonography of the dog and cat. London: Manson, 2000. p.83-108.

RAINOV, N.G.; WEISE, J.B.; BURKERT, W. Transcranial Doppler sonography in adult hydrocephalic patients. Neurosurg. Rev., v.23, p.34-38, 2000.

SAITO, M.; OLBY, N.J.; SPAULDING, K. et al. Relationship among basilar artery resistance index, degree of ventriculomegaly, and clinical signs in hydrocephalic dogs. Vet. Radiol. Ultrasound, v.44, p.687-694, 2003.

SELBY, L.A.; HAYES, H.M.; BECKER, S.V. Epizootiologic features of canine hydrocephalus. Am. J. Vet. Res., v.40, p.411-413, 1979.

SEO, M.; CHOI, H.; LEE, K. et al. Transcranial Doppler ultrasound analysis of resistive index in rostral and caudal cerebral arteries in dogs. $J$. Vet. Sci., v.6, p.61-66, 2005.

SPAULDING, K.A.; SHARP, N.J.H.

Ultrasonographic imaging of the lateral cerebral ventricles in the dog. Vet. Radiol., v.31, p.59-64, 1990.

TUCKER, R.L.; GAVIN, P.G. Brain imaging. Vet. Clin. N. Am. Small Anim. Pract., v.26, p.735-758, 1996. 